RESEARCH PAPER RP679

Part of Bureau of Standards Journal of Research, vol. 12, May 1934

\title{
HOSIERY TESTING MACHINE
}

\author{
By Herbert F. Schiefer and William D. Appel
}

\section{ABSTRACT}

The machine described in this paper provides a convenient means for measuring the behavior of a woman's full-fashioned stocking when the upper part of the leg of the stocking is repeatedly distended in a way which subjects it to forces similar to those which occur at the knee and at the garter clasps of a stocking in use. Two smooth "jaws" are inserted in the upper part of the stocking. It is held by two garter clasps attached at the welt and by a weight fastened to the ankle. The jaws are repeatedly separated and brought toward each other by a reciprocating mechanism in such a way that the circumference of the stocking, that is, the distance around the jaws, is varied between 13.3 and 21.3 inches. Means are provided for recording on a chart the relationship between the load exerted on the stocking and the circumference of the stocking for each cycle of loading and unloading. The number of cycles is recorded by a counter. The test may be continued until holes or runs are produced in the stocking.

Typical results of tests are given. The effect of laundering on the behavior of the stockings is also shown.

\section{CONTENTS}

1. Introduction

II. The machine. 544

III. Calibration

IV. Test procedure

V. Illustrative tests

VI. Discussion and application

\section{INTRODUCTION}

When, early in 1933, the General Federation of Women's Clubs undertook the development of a specification for women's full-fashioned hosiery as a basis for the labeling of standard grades, the federation requested the Bureau of Standards to provide suitable test methods. Among the properties for which tests were requested were elasticity, bursting strength, and ability to resist runs. Since existing test methods and equipment did not appear to be adequate for the purpose, a new testing machine was developed. This machine is described here and some typical results obtained with it are given. The results indicate that the machine should be of value not only for the purposes of the specification, but also for the study and control of hosiery in the course of manufacture. With suitable modifications, the machine should be useful for testing other types of knitted fabrics and garments.

A woman's stocking must be capable of considerable distention in the region of the welt and upper leg if it is to give satisfactory service. Further, it should be sufficiently elastic to accommodate itself to the shape of the leg of the wearer and it should not lose this elasticity and 
become baggy after a period of use. A stocking is no longer satisfactory when a hole or run appears in it or when it ceases to fit the wearer. Failure occurs frequently at the knee of the stocking and at or near the point of attachment of the garter where maximum stresses are developed in the fabric.

These considerations led to the selection of the upper part of the leg of the stocking, including the welt, as the portion to be tested. The possibility of testing specimens of the fabric cut from the stocking was considered, but there would arise the problem of how to clasp the specimen. Further, it was desired to test the whole article, including the seam, by subjecting it to forces similar to those acting on the stocking in use. This appears to have been accomplished in the test to be described. The magnitudes of these forces vary with the build of the wearer, the position assumed by her, the number and location of attachment of garter clasps, as well as the dimensions of the stocking and the nature of the fabric of which it is made. The forces in the machine test probably approach those likely to develop under the most drastic reasonable conditions of use.

The machine permits the upper part of the leg of a stocking to be repeatedly distended. It provides means for recording on a chart the relationship between the load and circumference for each cycle of loading and unloading. Stockings having constructions considered to be standard in the industry have not developed defects in 2,000 to 5,000 cycles on the machine. Inferior stockings develop holes or runs in a very few cycles.

\section{THE MACHINE}

The hosiery testing machine is shown in figure 1. The upper part of the stocking, $A$, is slipped over two jaws, $B$ and $C$. Two garter clasps, $D$, which are attached to opposite sides of the welt, are connected through a spring to the toggle, $E$. The toggle is connected to the two jaws. A cord, to which is attached a weight, $W$, is fastened to the ankle of the stocking.

The surface of each jaw is polished. The cross section is semicircular. The diameter is 2 inches for a length of 8 inches and then gradually tapers off over the remaining 4 inches to the tip. The lower jaw, $B$, is fastened to a vertical rod, $G$, which in turn is connected through a connecting rod, $R$, to the crank disk, $H$, of the electric motor and reduction gear, $I$. The lower jaw is moved up and down by the motor at the rate of 60 cycles per minute. The amplitude of the movement of the lower jaw may be varied by varying the throw of the crank. The distance between the two jaws can be adjusted by the screw, $F$. For the standard test the minimum distance between the jaws is 3.5 inches and the throw of the crank is 2 inches. The minimum and maximum circumferences, distances around the jaws, are therefore 13.3 and 21.3 inches, respectively.

The upper jaw, $C$, is fastened to a vertical rod which in turn is supported by a disk, $J$, on the spring, $K$. The load which a stocking exerts on the upper jaw is transmitted by the rod to the top of the spring or it may be transmitted by the rod directly to the support, $M$, by rotating the disk, $L$, through a small angle. The compression of the spring is recorded on the chart, $P$, of stylograph paper by a steel needle fastened to one end of the lever, $N$. The contact between the 
B.S. Journal of Research, RP679

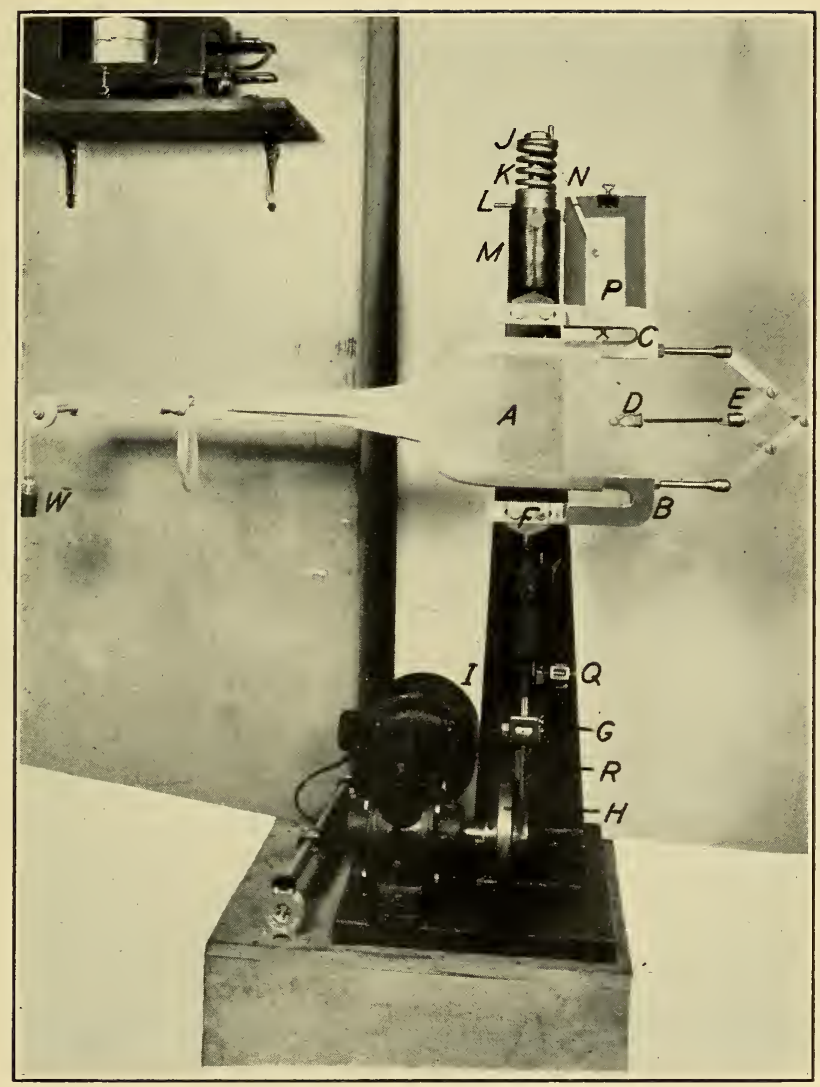

Figure 1.-Hosiery testing machine with stocking in place partly distended. 


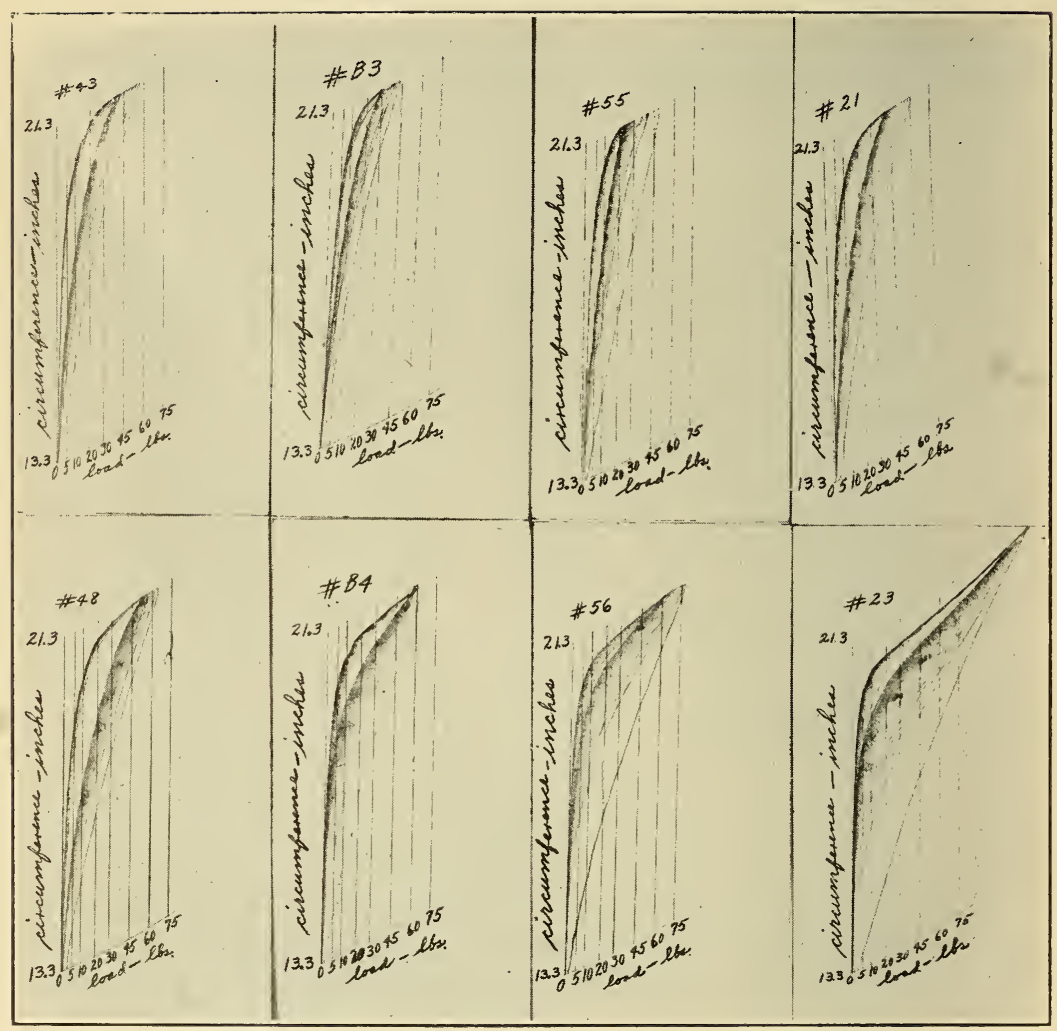

FigURe 3.-Typical records of silk hosier?.

The top row is for stockings as received from the retail stores. The bottom row is for duplicat atoc': $: \mathrm{n}$ after laundering. (See table 1.) 
needle and the chart may be broken by a cam. The compression of the spring is magnified 15 times and is recorded as a circular arc. The chart, which is attached by an extension rod to $G$, is moved up and down simultaneously with the lower jaw. The movement of the lower jaw is recorded on the chart by a vertical line. The relationship between the load on the stocking and the circumference of the stocking is recorded as a closed curve for each cycle. The number of cycles is recorded by the counter, $Q$.

The tension which is exerted by each garter clasp varies with the weight, $W$, and with the maximum circumference. It is approximately equal to 5 pounds when the weight is equal to 1 pound and the maximum circumference is equal to 21.3 inches.

\section{CALIBRATION}

To calibrate the spring, $K$, loads are placed on top of the disk, $J$, and the corresponding compressions of the spring are recorded on the chart. The calibration shown in figure 2 is based upon 20 calibrations. The variation between calibrations is less than 1 percent. The vertical lines correspond to various loads, and the circular arcs correspond to various circumferences. A correction has been applied for the slight decrease in circumference due to the compression of the spring. For reading the load or circumference from the chart it is convenient to use a transparent photographic reproduction of the calibration.

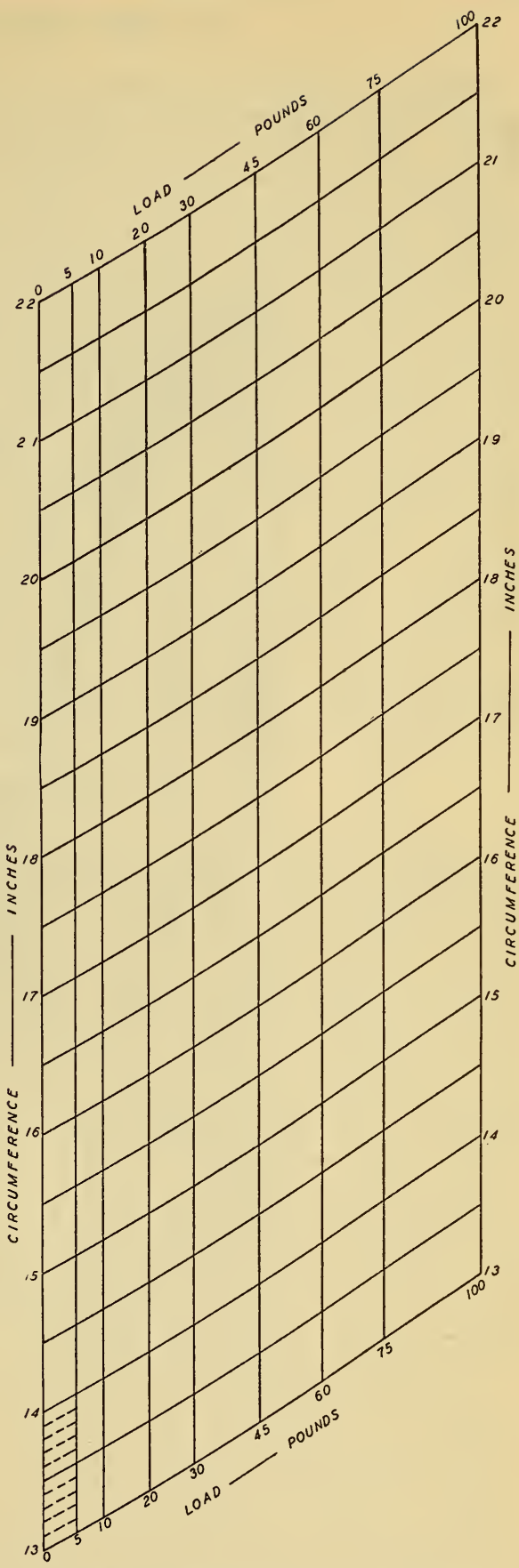

FIgURE 2.-Calibration chart of the hosierytesting machine. 


\section{TEST PROCEDURE}

Before a stocking is placed on the jaws for test the machine is operated for a few cycles to record a vertical line corresponding to zero load. The machine is then stopped with the distance between the jaws at a minimum and a short arc is recorded on the chart by compressing the spring slightly. This arc denotes the position on the chart corresponding to the minimum circumterence of 13.3 inches. The stocking is then placed on the jaws and the two garter clasps are attached to opposite sides of the welt midway between the jaws and 1 inch in from the top edge or selvage. The cord to which the weight of 1 pound is fastened is attached to the ankle of the stocking 2 to 3 inches above the bottom of the heel. The counter is set at zero. The machine is started and the stocking is repeatedly distended to a maximum circumference of 21.3 inches. Two hundred or any other convenient number of cycles are recorded on the chart, when the needle is lifted off and the load is transferred from the spring directly to the support, $M$. This change can be made without stopping the machine. The test is continued until a hole or run is produced in the stocking, or to any predetermined number of cycles, e.g., 1,000.

It is assumed that tests made with the hosiery-testing machine will be carried out on stockings that are in equilibrium with an atmosphere having a relative humidity of $65 \pm 2$ percent and a temperature of 70 to $80 \mathrm{~F}$, the standard conditions for textile testing.

\section{ILLUSTRATIVE TESTS}

In figure 3 are shown the charts which were obtained by testing silk stockings of four different kinds. The stockings were tested as received from the retail stores, top row, and after laundering, bottom row. The stockings were repeatedly distended from 13.3 to 21.3 inches in circumference. The weight, $W$, was equal to 1 pound. The tests were discontinued after 1,000 cycles unless failure occurred at fewer number of cycles. The first 200 cycles are recorded on the charts, except no. 56, where failure occurred at 115 cycles. The laundering treatment appears to have a great effect on the relationship between load and circumference. This is particularly true of the chiffon type represented by nos. 55 and 56 and of the service type represented by nos. 21 and 23. After laundering a greater load is required to distend the stockings to a given circumference. Stockings nos. B4, 56, and 23 became permanently deformed or baggy as shown, for example, by the great increase in circumference at a load of 10 pounds. Stockings nos. 56 and 23 developed holes and runs at an early stage of the test (see table 1 ).

In figure 4 is shown the test record of a "skimped" silk stocking, that is, one knit with too little silk in one course or circumference, tested as received from the retail store. This record is of interest, not only because the stocking failed at an early stage of the test, 117 cycles, but also because the maximum load decreases with each succeeding cycle to a minimum and then increases again and finally becomes greater than it was for the first cycle. Because of the use of too little yarn in this stocking, the silk is stretched beyond the elastic limit during each cycle, the stocking becomes very baggy, and has a harsh, stiff feel in contrast to the soft, pliable feel of the untested 


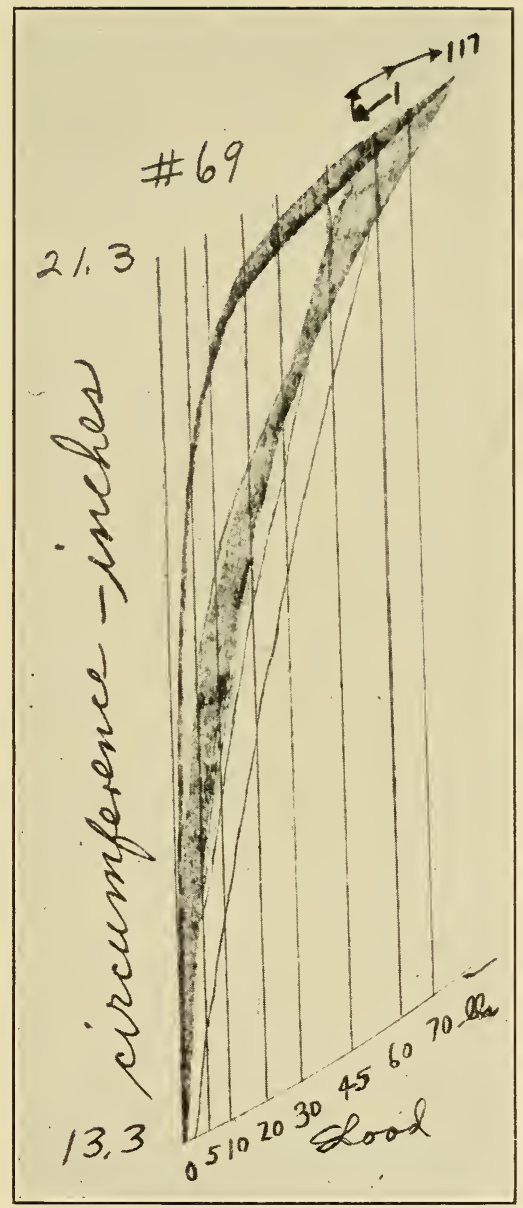

FIGURE 4:-Test record of a skimped silk stocking: 
stocking. The variation of the maximum load with the number of cycles, namely, a gradual decrease for several cycles and then a gradual increase to a value greater than that of the first cycle, is probably partly due to a change in the character of the surface of the silk as indicated by the harsh feel and partly due to a change in the internal structure of the silk as indicated by the stiff feel. An X-ray study of the silk before and after testing should yield interesting and valuable information relative to changes in the internal structure of the silk.

\section{DISCUSSION AND APPLICATION}

For a stocking to give satisfactory service it should meet the following requirements:

1. It should contain sufficient yarn in one course or circumference, that is, it should not be skimped.

2. It should have sufficient extensibility and elasticity, that is, it should stretch and yet not become permanently deformed or baggy as a result of stretching.

3. It should have sufficient durability, that is, it should not develop holes or runs when it is repeatedly distended.

A stocking which is skimped exerts a greater load when it is distended to a given extent than one which is not skimped but made from the same size yarn. Compliance with the first requirement can be determined, for a given weight stocking, by (a) specifying a maximum permissible load at the maximum distention of the first cycle, (b) specifying a minimum permissible circumference at a given load, e.g., 30 pounds, of the first cycle, and (c) specifying a maximum permissible amount of work expended during loading of the first cycle as given by the area under the loading curve and the zero load line.

When a stocking becomes permanently deformed or baggy during a test, the loading curves of the different cycles gradually approach the zero load line. Compliance with the second requirement for a given weight stocking can be determined by (a) specifying a maximum permissible circumference at a given load, e.g., 10 pounds, of the loading curve after a given number of cycles, e.g., 200 cycles, (b) specifying a minimum permissible value for the ratio of the work expended during loading of the 201st cycle to that expended during loading of the 1st cycle.

Compliance with the third requirement can be determined by specifying a minimum number of cycles, e.g., 1,000, which the stocking must withstand without the development of holes or runs.

In table 1 are summarized the results of the tests on four different kinds of silk stockings. The numbers correspond to the numbers contained on the test records shown in figure 3. The data show the great variations in the physical properties and quality of popular commercial stockings. They indicate the need of a comprehensive study of the effect of the various factors on the behavior of the stocking. A few of the factors which obviously will have an effect are the following: 1 , size or weight of the yarn; 2 , twist in the yarn; 3 , nature of the fiber in the yarn; 4 , total number of wales or loops in one course or circumference of the stocking; 5 , gage or size of each wale or loop; and 6 , nature and amount of finishing material in the stocking. The results of a systematic study of the effect of the various factors should be of inestimable value to manufacturers, distributors, and users of hosiery. 


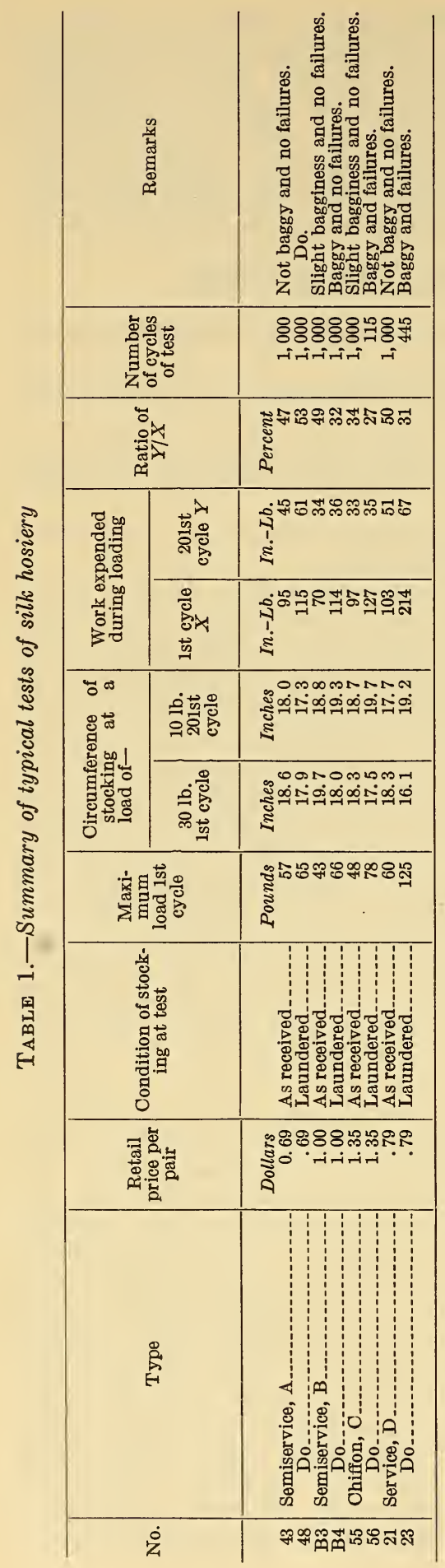


The results given indicate what may be expected from the use of the hosiery testing machine. ${ }^{1}$ The machine should be of value to manufacturers for the control of hosiery in the course of manufacture and for a systematic study of the effect of such factors as yarn size, yarn twist, hosiery gage, total number of wales in one course, degumming, dyeing, finishing, and laundering on the properties of the stocking. It should be useful to testing laboratories for conducting routine and commercial testing of hosiery. Finally, this machine provides a basis for specifying standard grades of hosiery in terms of performance and, therefore, should be of particular interest to the users of hosiery.

Washington, March 3, 1934.

1 Drawings showing the details of construction of the hosiery testing machine may be obtained from the textile section of the Bureau of Standards upon request. 